\title{
Retinal branch vein occlusion: a study of argon laser photocoagulation in the treatment of macular oedema
}

\author{
J. S. SHILLING AND C. A. JONES
}

From the Retinal Diagnostic Department, Moorfields Eye Hospital, City Road, London EC1V 2PD

SUMMARY A control trial is reported which demonstrates that treatment with argon laser photocoagulation to certain patients with macular oedema following a branch vein occlusion does not alter significantly their visual prognosis. It confirms that patients with an intact perifoveal capillary arcade have a better prognosis than those with a broken arcade.

Retinal branch vein occlusion is a common vascular event the natural history of which been well documented. The most common causes of poor visual acuity are neovascularisation producing vitreous haemorrhage and macular oedema. Macular oedema has been reported in $60 \%$ of patients following branch vein occlusion, ${ }^{1}$ although it becomes chronic in only $2 / 3$ of these. A study of the natural history of branch vein occlusion has emphasised the importance of the site of occlusion, size of vessel occluded, and the integrity of the perifoveal capillary arcades in predicting the visual prognosis. ${ }^{2}$ An intact perifoveal capillary arcade is associated with a good visual prognosis, whereas a poor visual outcome can be expected with a broken or incomplete arcade. Different therapeutic regimens have been proposed to relieve venous obstruction including the use of anticoagulants, ${ }^{34}$ low molecular weight dextrans, ${ }^{5}$ defibrinating agents, ${ }^{6}$ and clofibrate (Atromid-S), ${ }^{7}$ but their value has not been conclusively demonstrated. The efficacy of aspirin and dipyridamole is still being assessed.

It has been suggested that photocoagulation is effective in the treatment of both macular oedema and new vessel formation. The aim of this study was to assess in a control trial the efficacy of argon laser photocoagulation in altering the visual prognosis after a branch vein occlusion in which visual acuity was reduced due to macular oedema.

Correspondence to Mr J. S. Shilling.

\section{Material and methods}

Two populations of patients were included in the study. The first group presented within 3 months of the branch vein occlusion. Candidates were entered into the trial if their vision was $6 / 18$ or worse and if on fluorescein angiography the perifoveal capillary arcade was broken. A second larger group had been followed up for at least one year after a branch vein occlusion as part of a natural history study and were then considered for admission if their vision was 6/18 or worse. This group included patients with either intact or broken perifoveal capillary arcades. Patients with pre-existing eye disease likely to affect vision were excluded from the trial.

Patients admitted to the trial were allocated to a treatment or control group by standard randomisation techniques. Examination on admission included corrected visual acuity, slit-lamp biomicroscopy, ophthalmoscopy, and colour photography. Fluorescein angiography was performed on all patients. Those patients assigned to the treatment group received photocoagulation with argon laser to all areas containing leaking capillaries, but the foveola was avoided. Large leaking veins were treated along their margins. Nonleaking preferential channels were avoided and nonperfused areas were not specifically treated. All treatment was performed by the same person (J.S.). Further treatment was given at subsequent visits if the initial treatment failed-that is, if there was persistent 
leakage of fluorescein or the development of new foci of dye leakage. Patients in the control group were seen at 3-monthly intervals, those in the treatment group were seen 6-weekly until treatment was completed and 3-monthly thereafter. The chi-squared test for significance of the visual change was applied ${ }^{8}$ to compare the treated group with the control group; a difference of 1 or 2 lines was taken to indicate a change in vision at both 1 and 2 years following entry into the trial.

\section{Results}

Twenty-seven patients were seen within 3 months of the onset of a branch vein occlusion, 5 patients were lost to follow-up after one year, and of the remainder 13 patients had been treated and 9 formed the control group. After 2 years a further 12 patients were lost from the trial; of those remaining 7 had been treated and 3 were controls. The long-term component of the trial-i.e., those patients who had been followed up for at least one year before being incorporated into the trial-consisted of 63 patients; 8 patients were

Table 1

\begin{tabular}{llrll}
\hline & Treated & Controls & $p$ \\
\hline Visual change at l year & & & & \\
1-line change & Better & 21 & 17 & \\
& Same & 16 & 13 & \\
2-line change & Worse & 5 & 5 & 0.95 \\
& Better & 13 & 10 & \\
Sisual change at 2 years & Same & 26 & 22 & \\
1-line change & Worse & 3 & 3 & 0.96 \\
& Better & 15 & 5 & \\
2-line change & Same & 6 & 6 & \\
& Worse & 1 & 3 & 0.13 \\
& Better & 6 & 2 & \\
& Same & 16 & 9 & \\
& Worse & 0 & 2 & 0.22 \\
\hline
\end{tabular}

Table 2

\begin{tabular}{lllll}
\hline & Treated & Controls & $p$ \\
\hline Visual change at 1 year & & & & \\
1-line change & Better & 8 & 6 & \\
& Same & 5 & 2 & \\
Worse & 0 & 1 & 0.53 \\
2-line change & Better 6 & 5 & \\
& Same 7 & 3 & \\
Visual change at 2 years & Worse & 0 & 1 & \\
1-line change & Better & 5 & 2 & \\
& Same & 2 & 0 & \\
2-line change & Worse & 0 & 1 & 0.38 \\
& Better 3 & 2 & \\
& Same & 4 & 0 & 0.23 \\
\hline
\end{tabular}

lost to follow-up in the first year. Twenty-nine patients formed the treated group and 26 patients were controls. A further 30 were lost from the trial in the second year and of the remainder 15 had been treated and 10 were controls. Patients forming the long-term group were divided into those with broken and intact perifoveal capillary arcades. The visual acuity change in these 2 groups was compared. On analysis those patients who had been treated did not have significantly better vision than the control group considering 1 or 2 line difference as a change at either 1- or 2-year follow-up. Separate analysis of those treated within 3 months of a branch vein occlusion produced a similar result (Tables 1 and 2). Within both the treatment and control groups those with intact arcades had a significantly better visual prognosis than those with broken arcades (Tables 3 and 4).

The majority of patients had a reduction in macular oedema after treatment (Table 5). Within the control group $2 / 3$ of the patients seen within 3 months of a branch vein occlusion had less macular oedema at the end of the trial, but most patients who had a branch vein occlusion for at least one year prior to inclusion into the trial showed no reduction in macular oedema by the end of the trial period.

Table 3

\begin{tabular}{llcl}
\hline & Broken arcades & Intact arcades & $p$ \\
\hline Long-term control & group & 1-line visual change at 2 years & \\
Better & 0 & 3 & \\
Same & 4 & 0 & \\
Worse & 2 & 0 & $0 \cdot 04$ \\
Better & 0 & 3 & \\
No Better & 6 & 0 & $0 \cdot 01$ \\
\hline
\end{tabular}

Table 4

\begin{tabular}{lccc}
\hline & Broken arcades & Intact arcades & $p$ \\
\hline Long-term treated & group: & 2-line change at & years \\
Better & 0 & 3 & \\
Same & 11 & 1 & \\
Worse & 0 & 0 & 0.01 \\
Better & 0 & 3 & \\
No Better & 11 & 1 & 0.01 \\
\hline
\end{tabular}

Table 5

Treated Controls Undocumented cases

Three-month trial group

Macula oedema improved

Macula oedema unchanged $\quad 6 \quad 30$

Long-term trial group

Macular oedema improved 21

Macula oedema unchanged 11

7

$18 \quad 6$ 
Table 6 Patients with visual deterioration

\begin{tabular}{|c|c|c|c|c|}
\hline $\begin{array}{l}\text { Initial } \\
\text { vision }\end{array}$ & $\begin{array}{l}\text { Visual } \\
\text { loss }\end{array}$ & Cause & Arcades & Group \\
\hline $6 / 60$ & 2 lines & Vitreous haemorrhage & Intact & Control \\
\hline $6 / 24$ & 2 lines & Exudates & Broken & Control \\
\hline $6 / 60$ & 2 lines & Macular oedema & Broken & Control \\
\hline $6 / 60$ & 2 lines & Vitreous haemorrhage & Broken & Control \\
\hline $6 / 24$ & 1 line & Macular oedema & Broken & Treated \\
\hline $6 / 60$ & 2 lines & Macular oedema & Broken & Control \\
\hline $6 / 60$ & 2 lines & Macular oedema & Broken & Treated \\
\hline $3 / 60$ & 2 lines & Macular oedema & Broken & Treated \\
\hline $6 / 60$ & 2 lines & Exudates disciform & Broken & Treated \\
\hline $6 / 60$ & 2 lines & Macular oedema & Broken & Control \\
\hline $6 / 36$ & 1 line & RPE disturbance & Broken & Control \\
\hline $6 / 18$ & 2 lines & Exudates & Broken & Control \\
\hline
\end{tabular}

RPE = retinal pigment epithelium.

Those patients whose vision deteriorated during the trial were reviewed (Table 6). Only 1 of the 12 patients had an intact perifoveal capillary arcade, the visual reduction occurring as a result of a vitreous haemorrhage. Approximately equal numbers of treated and control patients experienced a reduction in vision.

\section{Discussion}

Macular oedema is a major cause of poor vision after a branch vein occlusion, and a number of authors have suggested photocoagulation, treating either the whole area of the branch vein occlusion or placing a barrier to prevent oedema fluid from diffusing towards the macula. The majority have used a technique whereby photocoagulation was applied to the areas of leaking capillaries, and it was this technique that was employed in this study.

Many authors have reported the results of such treatment for macular oedema following a branch vein occlusion. Krill et al..$^{9}$ treated 5 cases, 3 of which had subsequent improvement in vision. Campbell and Wise ${ }^{10}$ reported on 20 patients, $3 / 4$ of whom had an improvement in vision after treatment. Larger groups of patients have been treated by Blankenship and Okun ${ }^{11}$ and Cleasby et al. ${ }^{12}$; they all report favourably on the results of treatment. Sedney ${ }^{13}$ reports that $84 \%$ of patients treated with photocoagulation had an improvement in vision compared with $52 \%$ of untreated patients. None of these reports had a control group for comparison, and specific criteria for treatment were used. Other authors have reported less favourably. Wetzig ${ }^{14}$ treated 28 patients with macular oedema; $40 \%$ had an improvement in vision, but he compares this with $67 \%^{15}$ and $50 \%{ }^{16}$ improvement in 2 natural history studies of untreated patients.

The trial reported in this paper shows that treatment with argon laser photocoagulation to areas of retina with incompetent capillaries does not significantly improve the visual prognosis in certain patients with macular oedema following branch vein occlusion. The results of the study do not allow comment on the efficacy of treatment before 3 months of the onset of the disease in those patients with good initial visual acuity whose vision deteriorates, or on other techniques of photocoagulation. The study confirms that patients with an intact perifoveal arcade have a better visual prognosis than those with a broken arcade.

\section{References}

1 Greer DV, Constable IJ, Cooper RL. Macula oedema and retinal branch vein occlusion. Aust J Ophthalmol 1980; 8: 207-9.

2 Clemett RS, Kohner EM, Hamilton AM. The visual prognosis in retinal vein occlusion. Trans Ophthalmol Soc UK 1973; 93: 523-35.

3 Duff IF, Falls HF, Linman JW. Anticoagulant therapy in occlusive vascular disease. Arch Ophthalmol 1951; 46: 601-17.

4 Vannas S, Raitta C. Anticoagulant treatment of retinal vein obstruction. Am J Ophthalmol 1966; 62: 874-84.

5 Radnot $M$. Rheomacrodex in the treatment of occlusion of the central retinal vein. Ann Ophthalmol 1969; 1: 52-64.

6 Lindake HI, Masler SR. Therapy of retinal vein occlusion: use of fibrinolysin and anticoagulants. Am J Ophthalmol 1961; 51: 456-63.

7 Clements DB, Elsby JM, Smith WD. Retinal vein occlusion: a comparative study of factors affecting the prognosis including a therapeutic trial of Atromid S. Br J Ophthalmol 1968; 52: 111-6.

8 Armitage P. Statistical methods in medical research. Oxford: Blackwell, 1971.

9 Krill AE, Archer D, Newell F. Photocoagulation in complications secondary to branch vein occlusion. Arch Ophthalmol 1971; 85: 48-60.

10 Campbell CJ, Wise GN. Photocoagulation therapy of branch vein obstructions. Am J Ophthalmol 1973; 75: 28-31.

11 Blankenship GW, Okun E. Retinal tributary vein occlusion: history and management by photocoagulation. Arch Ophthalmol 1973; 89: 363-8.

12 Cleasby GW, Hall DL, Fung WE, Webster RG. Retinal branch vein occlusion, treatment by photocoagulation. Mod Probl Ophthalmol 1974; 12: 254-60.

13 Sedney SC. Photocoagulation in retinal vein occlusion. The Hague: Junk, 1976.

14 Wetzig PC. The treatment of acute branch vein occlusion by photocoagulation. Am J Ophthalmol 1979; 87: 65-73.

15 Michels RG, Gass JDM. The natural course of retinal branch vein obstruction. Trans Am Acad Ophthalmol Otolaryngol 1974; 78: 166-77.

16 Gutman FA, Zegarra $H$. The natural course of temporal branch vein occlusion. Trans Am Acad Ophthalmol Otolaryngol 1974; 78: $178-92$. 